\title{
Texture inheritance in thin-film growth of $\mathrm{Cu}_{2} \mathrm{ZnSnS}_{4}$
}

\author{
A. Weber, ${ }^{\text {a) }}$ S. Schmidt, D. Abou-Ras, P. Schubert-Bischoff, I. Denks, R. Mainz, and \\ H. W. Schock \\ Helmholtz-Zentrum Berlin für Materialien und Energie, Glienicker Str. 100, D-14109 Berlin, Germany
}

(Received 26 May 2009; accepted 9 July 2009; published online 29 July 2009)

\begin{abstract}
The growth mechanism of $\mathrm{Cu}_{2} \mathrm{ZnSnS}_{4}$ thin films is studied starting from highly textured $\mathrm{ZnS}$ precursor films. These precursors were converted to $\mathrm{Cu}_{2} \mathrm{ZnSnS}_{4}$ by subsequent deposition of $\mathrm{Cu}, \mathrm{Sn}$, and $\mathrm{S}$ at high temperatures. Orientation measurements revealed that the $\langle 111\rangle$ texture of the $\mathrm{ZnS}$ precursor is inherited by the $\mathrm{Cu}_{2} \mathrm{ZnSnS}_{4}$ layer. On the basis of texture and transmission electron microscopy measurements, a growth model is proposed. According to this model, the initial formation of $\mathrm{Cu}_{2} \mathrm{ZnSnS}_{4}$ nuclei is controlled by a topotactic or epitactic mechanism with respect to the $\mathrm{ZnS}$ precursor. The further growth of the $\mathrm{Cu}_{2} \mathrm{ZnSnS}_{4}$ grains appears to be independent of the precursor lattice. (C) 2009 American Institute of Physics. [DOI: 10.1063/1.3192357]
\end{abstract}

$\mathrm{Cu}_{2} \mathrm{ZnSnS}_{4}$ is a promising thin-film photovoltaic absorber material and the best solar cells of this compound have recently reached conversion efficiencies of $6.7 \%{ }^{1}$ The thermodynamically most stable crystal structure of $\mathrm{Cu}_{2} \mathrm{ZnSnS}_{4}$ is kesterite (space group $I \overline{4}$ ), ${ }^{2}$ which is similar to the chalcopyrite structure of $\mathrm{Cu}(\mathrm{In}, \mathrm{Ga}) \mathrm{Se}_{2}$ (space group $I \overline{4} 2 d) .{ }^{3}$ The latter compound is a well known photovoltaic absorber material, reaching efficiencies of up to $20 \%{ }^{4}$ The best absorber layers are formed in evaporation processes where a precursor layer of $(\mathrm{In}, \mathrm{Ga})_{2} \mathrm{Se}_{3}$ is transformed to $\mathrm{Cu}(\mathrm{In}, \mathrm{Ga}) \mathrm{Se}_{2}$ (Refs. 5 and 4$)$ in $(\mathrm{Cu}+\mathrm{Se})$ flux. It has been found earlier that a texture of the precursor layer also leads to a texture in the resulting absorber layer. ${ }^{6}$ This texture inheritance has been explained by the structural similarity of $\mathrm{In}_{2} \mathrm{Se}_{3}$ and $\mathrm{CuInSe} \mathrm{C}_{2}$. A similar effect has been proposed for the phase $\mathrm{Cu}_{2-x} \mathrm{Se}$, ${ }^{7-9}$ which is formed in Cu-rich films. These findings have led to the model that $\mathrm{CuInSe}_{2}$ (Ref. 8) and $\mathrm{Cu}(\mathrm{In}, \mathrm{Ga}) \mathrm{Se}_{2}$ (Ref. 9) can be grown from the precursor phases by a topotactic mechanism. This mechanism implies that the crystalline lattice and orientation of the precursor remain mostly unchanged, while only the atoms of specific lattice sites are exchanged. ${ }^{10} \mathrm{~A}$ topotactic mechanism is also plausible for the growth of $\mathrm{Cu}_{2} \mathrm{ZnSnS}_{4}$ from the precursors $\mathrm{ZnS}$ and $\mathrm{Cu}_{2} \mathrm{SnS}_{3}{ }^{11}$ These three phases can crystallize in the structure or a superstructure of sphalerite. ${ }^{12-15}$ In this letter we investigate the formation of $\mathrm{Cu}_{2} \mathrm{ZnSnS}_{4}$ starting from a $\mathrm{ZnS}$ precursor in order to clarify the atomistic mechanism of the reaction.

Precursor deposition and the subsequent transformation to $\mathrm{Cu}_{2} \mathrm{ZnSnS}_{4}$ were carried out in a physical vapour deposition system described elsewhere. ${ }^{16}$ Three $\mathrm{ZnS}$ precursors were deposited by evaporating $\mathrm{ZnS}$ on Mo-coated soda lime glass substrates. The substrate temperature was approximately $420 \mathrm{~K}$. After deposition of the $\mathrm{ZnS}$ layer, the three substrates were heated to $650 \mathrm{~K}$ and at constant temperature $\mathrm{Cu}, \mathrm{Sn}$, and $\mathrm{S}$ were evaporated simultaneously on the substrates. Earlier experiments ${ }^{16}$ had revealed a low Sn adsorption at these temperatures. Therefore a high $\mathrm{Sn} / \mathrm{Cu}$ evaporation ratio of approximately 1 was applied to avoid $\mathrm{Sn}$ deficiency in the layers. After defined periods of the evapo-

${ }^{a}$ Electronic mail: alfons.weber@helmholtz-berlin.de. ration process, the three substrates were successively removed from the deposition zone with a manipulator and cooled down rapidly. The morphology of the processed films was analyzed with a scanning electron microscope (SEM, LEO1530 Gemini). Texture measurements were performed on a diffractometer (Seifert MZ VI, tilting angle: $85^{\circ}>\psi$ $>0^{\circ}$ rotation angle: $355^{\circ}>\phi>0^{\circ}$, step width: $5^{\circ}$ ). The depth profile of the elemental composition was measured by energy dispersive $\mathrm{x}$-ray spectroscopy (EDX) in scanning mode on a transmission electron microscope (STEM) (Zeiss Libra 200FE). The same microscope was used for high resolution TEM (HRTEM) micrographs.

Figure 1 shows cross sections of the films after different deposition times. After 2.5 and 5.5 min evaporation, a bottom layer with columnar grains and high contrast in the SEM picture can be observed. Grains with significantly different SEM contrast and morphology can be found on top of this layer. After $20.5 \mathrm{~min}$, the bottom layer has disappeared.

To clarify the observed differences in the SEM contrast of the different layers, a STEM-EDX depth profile was measured. Figure 2 shows the result of an EDX linescan along the cross section of sample (b) from Fig. 1. In the top layer $\mathrm{Cu}, \mathrm{Zn}$ and $\mathrm{Sn}$ are homogeneously distributed throughout the depth of the layer. In the bottom layer, the $\mathrm{Zn}$ signal is strong and the $\mathrm{Sn}$ signal and $\mathrm{Cu}$ signal are in the range of the detection limit. The $\mathrm{S}$ signal is approximately constant throughout the layer. In diffraction measurements on this layer (not presented here), the kesterite superstructure reflexes could be identified clearly. From these results we derive that the top layer consists of $\mathrm{Cu}_{2} \mathrm{ZnSnS}_{4}$ while the bottom layer repre-

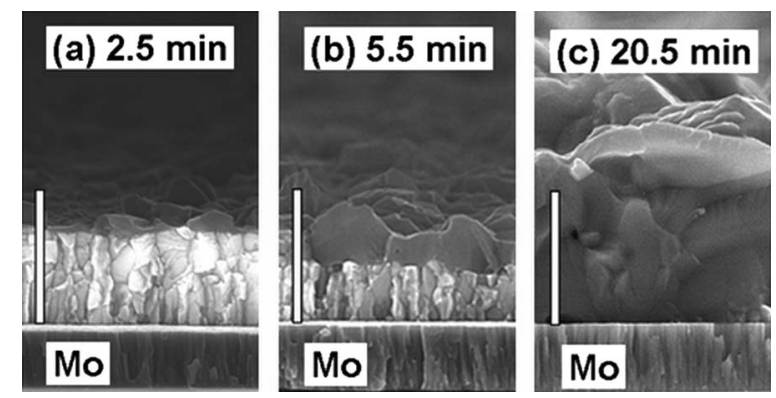

FIG. 1. SEM micrographs on cross sections of the $\mathrm{ZnS}$ precursors after different times of $(\mathrm{Cu}+\mathrm{Sn}+\mathrm{S})$ evaporation at $650 \mathrm{~K}$. The bars mark $1 \mu \mathrm{m}$. 


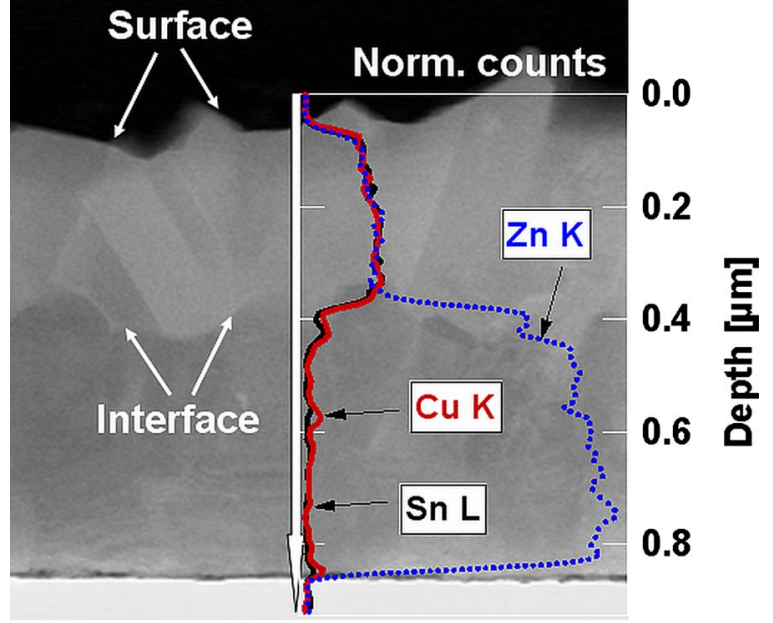

FIG. 2. (Color online) STEM-EDX depth profile on a cross section of the $\mathrm{ZnS}$ precursor after $5.5 \mathrm{~min}$ of $(\mathrm{Cu}+\mathrm{Sn}+\mathrm{S})$ evaporation.

sents the unreacted precursor $\mathrm{ZnS}$. In combination with Fig. 1, we conclude that the layers consist mainly of $\mathrm{ZnS}$ after $2.5 \mathrm{~min}$ and mainly of $\mathrm{Cu}_{2} \mathrm{ZnSnS}_{4}$ after $20.5 \mathrm{~min}$ of $(\mathrm{Cu}+\mathrm{Sn}+\mathrm{S})$ evaporation. This is confirmed by diffraction measurements where after $20.5 \mathrm{~min}$, the typical kesterite diffraction pattern ${ }^{12}$ could be found (not presented here).

In case of a topotactic formation of $\mathrm{Cu}_{2} \mathrm{ZnSnS}_{4}$ from $\mathrm{ZnS}$, the orientations of the precursor grains and of the $\mathrm{Cu}_{2} \mathrm{ZnSnS}_{4}$ grains are identical. A texture of the precursor layer would therefore also result in a comparable texture of the $\mathrm{Cu}_{2} \mathrm{ZnSnS}_{4}$ layer. Figure 3 shows the result of a texture measurement on the $\mathrm{ZnS}$ precursor after $2.5 \mathrm{~min}$ of $\mathrm{Cu}$ $+\mathrm{Sn}+\mathrm{S}$ ) evaporation. The measured figures are typical for a $\langle 111\rangle$ fiber texture of a cubic crystal structure.

The same measurement was performed for the $\mathrm{ZnS}$ precursor after $20.5 \mathrm{~min}$ of $(\mathrm{Cu}+\mathrm{Sn}+\mathrm{S})$ evaporation, i.e., for the $\mathrm{Cu}_{2} \mathrm{ZnSnS}_{4}$ (kesterite) layer. Kesterite is a tetragonally distorted superstructure of the cubic sphalerite, for reasons of simplification the $\{112\}$ planes of this system will be treated as $\{111\}_{\text {cub }}$ and the $\{200\} /\{004\}$ planes as $\{200\}_{\text {cub }}$. The resulting pole figures in Fig. 4 can be well explained by a double fiber texture in the directions $\langle 111\rangle_{\text {cub }}$ and $\langle 100\rangle_{\text {cub }}$.

On first sight, the pole figure measurements seem to prove a topotactic reaction mechanism because the $\langle 111\rangle$ fiber texture is inherited from the precursor to the product layer. But the formation of an additional $\langle 100\rangle$ fiber texture cannot be explained by this model. To clarify these contradicting findings, we investigated the interface between the (a) $\{111\}$

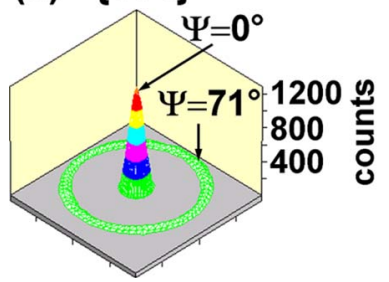

(b) $\{200\}$

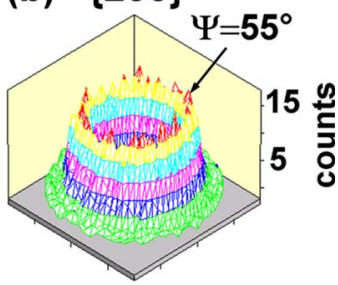

FIG. 3. (Color online) Pole figures for different diffracting planes of the $\mathrm{ZnS}$ precursor after $2.5 \mathrm{~min}$ of $(\mathrm{Cu}+\mathrm{Sn}+\mathrm{S})$ evaporation. The intensity rings are typical for a $\langle 111\rangle$ fiber texture in a cubic system (theoretical interplanar angle of $\{111\}$ planes: $70.5^{\circ}$, theoretical interplanar angle of $\{111\}$ and $\{200\}$ planes: $54.7^{\circ}$ ). (a) $\{111\}_{\text {cub }}$

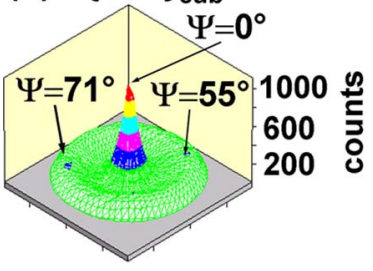

(b) $\{200\}_{\text {cub }}$

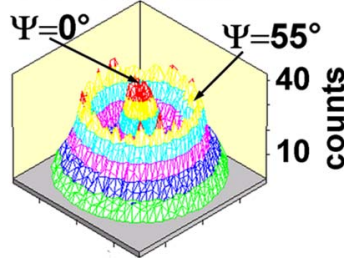

FIG. 4. (Color online) Pole figures for different diffracting planes of the $\mathrm{Cu}_{2} \mathrm{ZnSnS}_{4}$ layer after $20.5 \mathrm{~min}$ of $(\mathrm{Cu}+\mathrm{Sn}+\mathrm{S})$ evaporation. The intensity rings indicate a double fiber texture in the directions $\langle 111\rangle$ and $\langle 100\rangle$.

$\mathrm{ZnS}$ precursor and the $\mathrm{Cu}_{2} \mathrm{ZnSnS}_{4}$ layer with HRTEM. Figure 5 shows a HRTEM micrograph of this interface for the sample after $5.5 \mathrm{~min}$ of $(\mathrm{Cu}+\mathrm{Sn}+\mathrm{S})$ evaporation. The lattice planes of two $\mathrm{ZnS}$ grains can be discerned, with plane distances of about $0.3 \mathrm{~nm}$ and an intersecting angle of the planes of about $109^{\circ}$. These planes are therefore identified as $\{111\}$ sphalerite planes. For the $\mathrm{Cu}_{2} \mathrm{ZnSnS}_{4}$ grain, only one set of planes can be observed. These planes are tilted more than $15^{\circ}$ with respect to the $\mathrm{ZnS}$ planes. Two further measurements at different locations of the interface also showed no exact match between the orientations of $\mathrm{ZnS}$ grains and $\mathrm{Cu}_{2} \mathrm{ZnSnS}_{4}$ grains.

Because of (i) the different morphology of precursor and product, (ii) the appearance of an additional texture during processing, and (iii) the missing coherence of the lattice orientations of neighboring precursor grains and product grains, we assume that film growth is not solely based on a topotactic mechanism. We suggest the following growth model: in an initial stage, $\mathrm{Cu}_{2} \mathrm{ZnSnS}_{4}$ nuclei are formed on top of the $\mathrm{ZnS}$ layer. Via a topotactic or epitactic mechanism of the nucleation step, the underlying textured $\mathrm{ZnS}$ grains will induce preferably a $\langle 111\rangle_{\text {cub }}$ orientation in the nuclei. To some extent also $\langle 100\rangle_{\text {cub }}$ orientation will occur which may be due to a structural relationship between the $\langle 111\rangle_{\text {cub }}$ and $\langle 100\rangle_{\text {cub }}$ direction. With further processing the $\mathrm{Cu}_{2} \mathrm{ZnSnS}_{4}$ grains enlarge and overgrow neighboring $\mathrm{ZnS}$ grains. As neighboring $\mathrm{ZnS}$ grains exhibit a certain misorientation, incoherent $\mathrm{ZnS}-\mathrm{Cu}_{2} \mathrm{ZnSnS}_{4}$ interfaces will necessarily form. The further formation of $\mathrm{Cu}_{2} \mathrm{ZnSnS}_{4}$ in the film is most likely not controlled by the precursor lattice but by material transport through the already grown $\mathrm{Cu}_{2} \mathrm{ZnSnS}_{4}$ layer. This letter

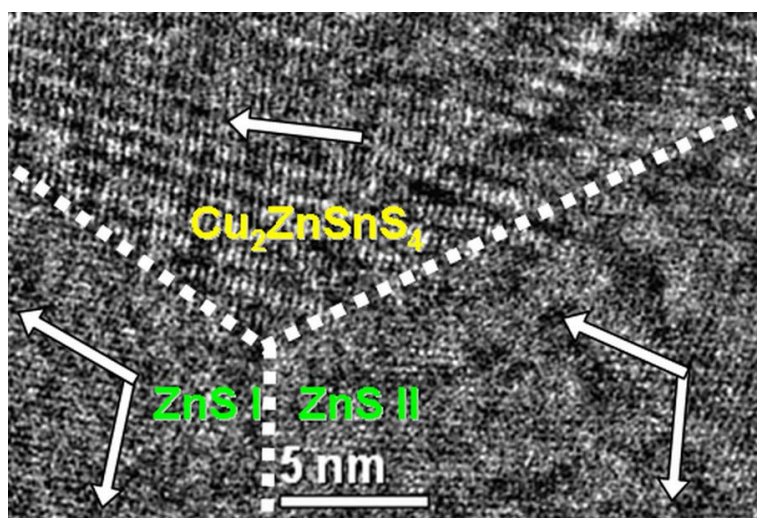

FIG. 5. (Color online) HRTEM micrograph of the $\mathrm{ZnS}-\mathrm{Cu}_{2} \mathrm{ZnSnS}_{4}$ interface after $5.5 \mathrm{~min}$ of processing. The arrows mark the normals of the observed lattice planes. The dotted lines mark the grain boundaries. The planes of the $\mathrm{Cu}_{2} \mathrm{ZnSnS}_{4}$ grain are tilted more than $15^{\circ}$ with respect to the $\mathrm{ZnS}$ planes. 
shows that a texture inheritance from the precursor is not necessarily coupled with an exclusively topotactic mechanism of the underlying chemical reaction.

${ }^{1}$ H. Katagiri, K. Jimbo, S. Yamada, T. Kamimura, W. S. Maw, T. Fukano, T. Ito, and T. Motohiro, Appl. Phys. Express 1, 041201 (2008).

${ }^{2}$ S. Chen, X. G. Gong, A. Walsh, and S. H. Wie, Appl. Phys. Lett. 94, 041903 (2009).

${ }^{3}$ S. Schorr, Thin Solid Films 515, 5985 (2007).

${ }^{4}$ M. A. Contreras, K. Ramanathan, J. A. Shama, F. Hasoon, D. L. Young, B. Egass, and R. Noufi, Prog. Photovoltaics 13, 209 (2005).

${ }^{5}$ S. Zweigart, S. M. Sun, G. Bilger, and H. W. Schock, Sol. Energy Mater. Sol. Cells 41, 219 (1996).

${ }^{6}$ M. A. Contreras, B. Egaas, D. King, A. Swartzlander, and T. Dullweber, Thin Solid Films 361-362, 167 (2000).

${ }^{7}$ R. Klenk, T. Walter, H. W. Schock, and D. Cahen, Adv. Mater. 5, 114
(1993).

${ }^{8}$ T. Wada, N. Kohara, T. Negami, and M. Nishitani, J. Mater. Res. 12, 1456 (1997).

${ }^{9}$ F. Hergert, S. Jost, R. Hock, and M. Purwins, J. Solid State Chem. 179, 2394 (2006).

${ }^{10}$ R. D. Shannon and R. C. Rossi, Nature (London) 202, 1000 (1964).

${ }^{11}$ F. Hergert and R. Hock, Thin Solid Films 515, 5953 (2007).

${ }^{12}$ S. R. Hall, J. T. Szymanski, and J. M. Stewart, Can. Mineral. 16, 131 (1978).

${ }^{13}$ M. Onoda, X. Chen, M. Sato, and H. Wada, Mater. Res. Bull. 35, 1563 (2000).

${ }^{14}$ J. C. Jamieson and H. H. Demarest, J. Phys. Chem. Solids 41, 963 (1980).

${ }^{15}$ C. Y. Yeh, Z. W. Lu, S. Froyen, and A. Zunger, Phys. Rev. B 46, 10086 (1992).

${ }^{16}$ A. Weber, H. Krauth, S. Perlt, B. Schubert, I. Kötschau, S. Schorr, and H. W. Schock, Thin Solid Films 517, 2524 (2009). 